\title{
Design and Construction of Wind Turbine-Solar Panel System Prototype for Water Supply Control
}

\author{
A. M. Shiddiq Yunus ${ }^{1, *, a}$, Musrady Mulyadi ${ }^{1, \mathrm{~b}}$, Apollo ${ }^{1, \mathrm{c}}$, Rifqy Rinaldi Wahid ${ }^{1}$, and Rima Zalsabillah ${ }^{1}$ \\ ${ }^{1}$ Mechanical Engineering Department, State Polytechnic of Ujung Pandang, Jalan Perintis Kemerdekaan KM.10, Tamalanrea, \\ Makassar, Indonesia \\ *,a shiddiq@poliupg.ac.id (Corresponding Author), ${ }^{\mathrm{b}}$ musrady_mulyadi@poliupg.ac.id \\ c apollo@poliupg.ac.id,
}

\begin{abstract}
Water supply is a crucial for human lives, not only for daily activities but also for secondary purposes such as for watering garden, paddy fields etc. There are many efforts of human in fulfilling their water supply needs. Most of water supply is provided by using electric motor pumps which in certain cases might increase the financial cost. In this paper, wind energy is applied to pumping water mechanically whilst it combines with solar panel which works to pump water during less wind speed condition. The micro-controller Arduino-Uno is employed to manage the collaboration operation between wind and solar panel. The design concept and construction are presented and discussed. The operation results exhibit good operation performance and could be developed for the real application.
\end{abstract}

Keywords-Solar Panel; Wind Turbine; Water Supply

\section{Introduction}

Water is the main requirement of agricultural activities. However, not all regions have adequate reserves or sources of clean water, therefore, many rice fields and plantations are highly dependent on rainwater (rice fields and rain fed gardens), consequently, if there is a dry season, the production process can decrease and harm farmers and disrupt government supplies. In order to overcome this problem, electric water pumps are usually an option, but of course long-term use is not economically effective because it is associated with the cost of the electricity bill [1].

The control system is a system consisting of one or more equipment that functions to control other systems related to a process. With the development of science and technology, the control system in the industrial world is also growing. This allows control of a process can be done automatically. One of the most widely used tools to control processes automatically is a microcontroller [2].

For small garden, for some specific plants such as spinach water is required continue to be served [3], if the gardens located on electrified region, an electrical pumps might be a solution. However, some regions in Indonesia still do not enjoy electric supply yet by about $0.6 \%$ in 2021 [4], therefore an alternative energy sources should be taken into consideration.

Wind energy is one promising renewable energy source for generating electric power. It has been installed about $817 \mathrm{GW}$ in 2020 [5] and predict to achieve about $1000 \mathrm{GW}$ in 2025 [6]. Savonius blade wind type is one of wind turbine types that are suitable for low wind speed and small scale wind turbine [7]. To achieve optimal performance of a system that use wind turbine a combination with solar panel system might be a necessary option.

Solar Energy becomes a favorite option to electrify an isolated area where power distribution line is not available. With is source available abundantly, solar energy from the sun could be extracted optimally in certain degrees position depends on its location [8]. In this paper, a design and construction of a combination between wind turbine and solar panels for water supply purpose will be introduced and discussed and the performance operation will be investigated through a testing and data collection process. 


\section{Research Methodology}

\section{A. Literature Review Stage}

The planning stage is a literature study on wind speed and related weather in the process of processing and data collection by solar panels with the aim of collecting information to facilitate the design work.

\section{B. Design Stage}

The tools to be designed are wind turbines and solar panels. By using a wind turbine, the mechanical power generated by the wind turbine is then used to drive the dragon pump. Pump is a device used to move fluid (liquid) based on the compressive force from one place. The dragon pump is installed with a flow meter to detect the water flowing in the dragon pump.

As it is known that the wind cycle is unpredictable, so if the dragon pump does not work the flow meter will send a signal to the servo motor located in the reservoir to open the tap on the reservoir. Previously, the reservoir was filled with water using a 12 volt DC pump whose electricity source was obtained from a solar panel. As is known, that sunlight is only available optimally for eight hours. By using control engineering, when the water discharge from the manual pump $=0 \mathrm{ml} / \mathrm{s}$, the servo motor in the reservoir automatically opens. As a result, the availability of clean water will remain if the dragon pump does not work. In this study, the type of solar panel used is with a capacity of $2 \times 50 \mathrm{WP}$.

\section{Construction and Installation Stage}

The next stage of this applied research is construction and installation based on the design results as shown in Figure 1.

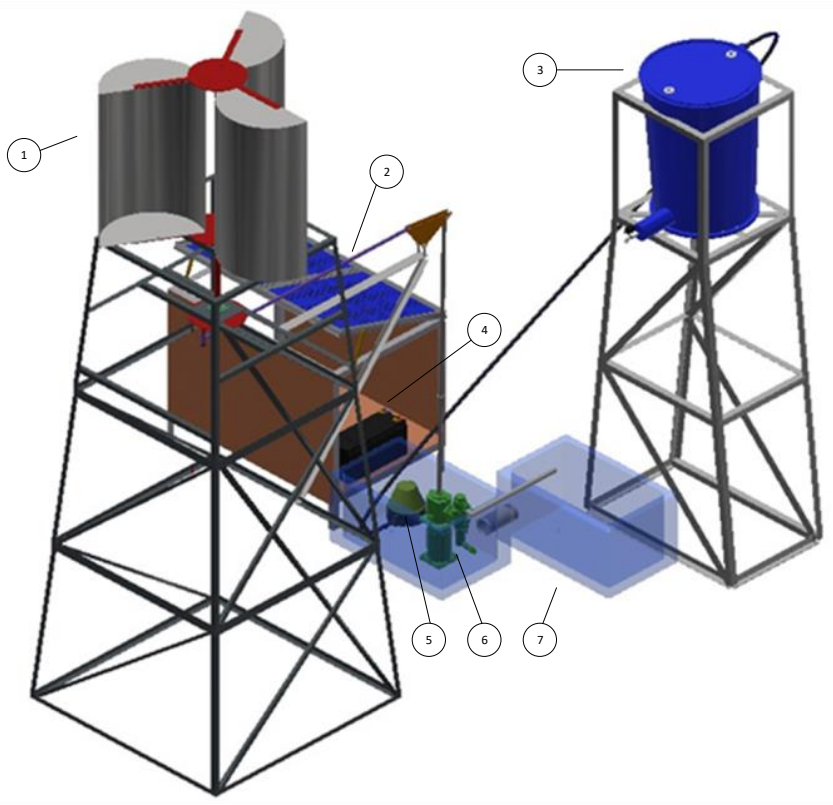

Figure 1. Applied 3D Sketches

Legend:

1. Turbine

2. Solar Panel

3. Drums

4. Battery/Accu

5. 12 V DC Pump

6. PVC Manual Pump

7. Water Outlet Reservoir

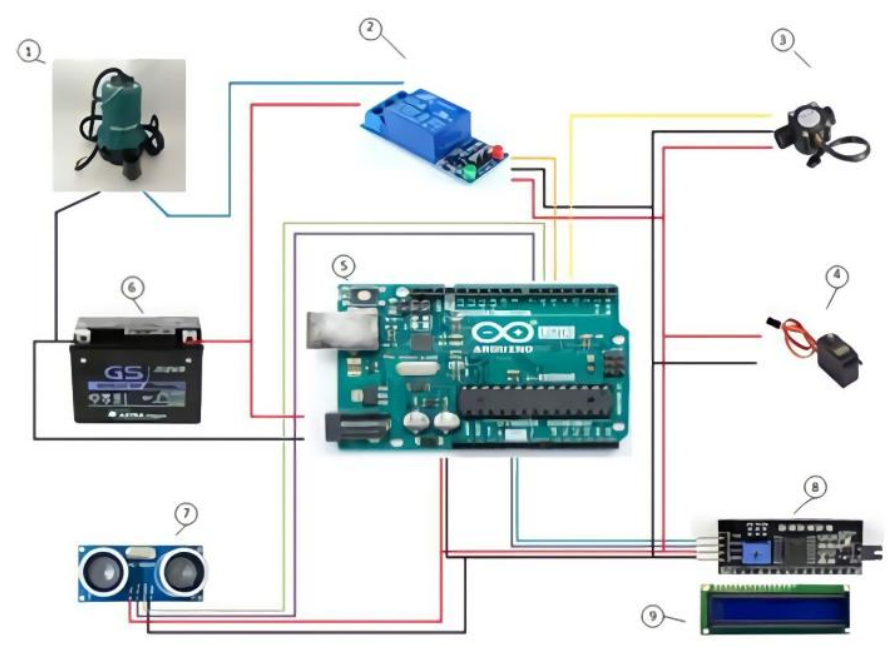

Figure 2. Schematic of Control Program 
Legend:

1. Submersible Water Pump 12V DC 800L/hr

2. Relay

3. Flowmeter

4. Servo motor

5. Arduino Uno

6. $12 \mathrm{~V}$ battery

7. Ultrasonic sensors

8. I2C

9. LCD

The control system for overall system is configured as shown in Figure 2. The main brain of all the inputs and outputs of the system is controlled by Arduino Uno.

\section{Results and Discussion}

The wind turbine converts the wind into mechanical energy through a triangular transmission so that the manual pump moves. Meanwhile, the solar panel functions to convert solar energy into electrical energy which is stored in the battery to run the control system. SCC is connected to the panel to regulate the current and voltage on the panel, battery and pump. The water flow from the pump enters the drum until the water level is 10 $\mathrm{cm}$ from the ultrasonic sensor. If the water level reaches $30 \mathrm{~cm}$ from the sensor, the pump automatically activates and refills the drum.

When the wind turbine is not moving, the servo motor on the drum opens. If there is a discharge reading on the flow meter sensor, the servo motor is closed.

The solar panel efficiency is calculated as follow:

$$
\begin{aligned}
& \eta=\frac{\text { Pout }}{\mathrm{G} \times \mathrm{A}} \times 100 \% \\
& \eta_{\text {panel }}=\frac{V_{\text {panel }} \times I_{\text {panel }}}{\mathrm{G} \times \mathrm{A}} \times 100 \% \\
& \eta_{\text {panel }}=\frac{19 \mathrm{~V} \times 0,32 \mathrm{~A}}{1026,5 \mathrm{~W} / \mathrm{m} 2 \times 1,08 \mathrm{~m}} \times 100 \% \\
& \eta_{\text {panel }}=0,55 \%
\end{aligned}
$$

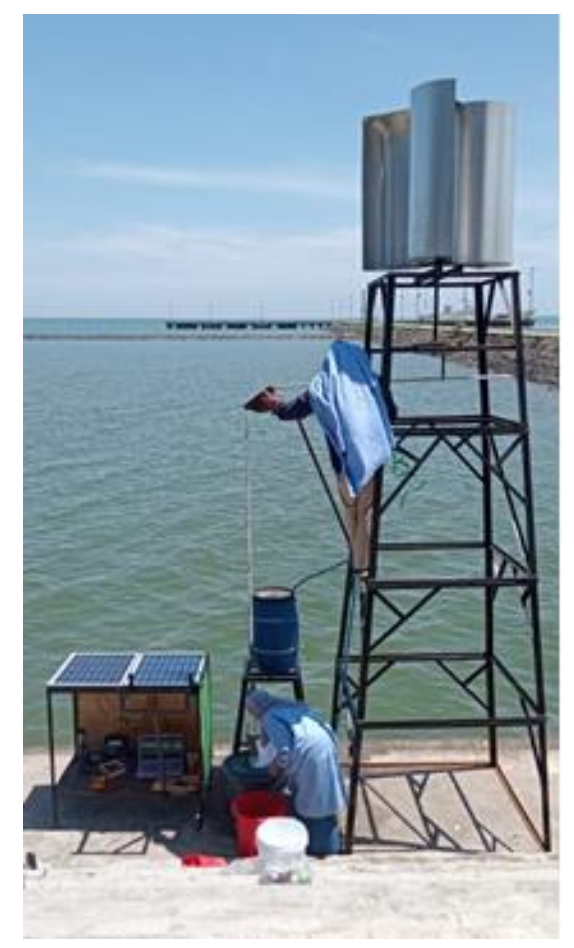

Figure 3. The real system after construction and Installation for data collection

The pump efficiency is calculated as follow:

$$
\begin{gathered}
\eta_{\text {pompa }}=\frac{\rho \times Q \times g \times H}{V_{\text {in }} \times I_{\text {in }}} \times 100 \% \\
\eta_{\text {pompa }}=\frac{997 \frac{\mathrm{kg}}{\mathrm{m}} \times 0,00022 \frac{\mathrm{m} 3}{\mathrm{~s}} \times 9,8 \frac{\mathrm{m}}{\mathrm{s}} \times 2 \mathrm{~m}}{14 \mathrm{~V} \times 2,25 \mathrm{~A}} \times 100 \% \\
\eta_{\text {pompa }}=13,65 \%
\end{gathered}
$$

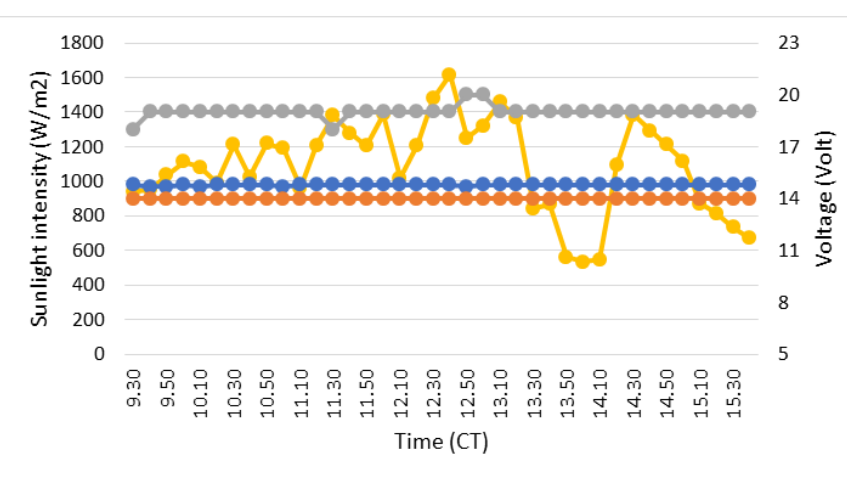

Figure 4. Relationship among panel voltage, battery voltage, pump voltage and sunlight intensity 
Figure 4 shows that the pump voltage is constant at 14 Volts, while the battery voltage, panel voltage, and solar radiation intensity fluctuate. The battery voltage at 9.30 Central Time (CT) to $15.40 \mathrm{CT}$ has an average value of 14.79 Volts, while the panel voltage at 9.30 CT to $15.40 \mathrm{CT}$ has an average value of 19 Volts. The highest value of solar radiation intensity is $1615.6 \mathrm{~W} / \mathrm{m} 2$ at $12.40 \mathrm{CT}$, while the lowest value of solar radiation is $\mathrm{n} 534.9 \mathrm{~W} / \mathrm{m} 2$ at $14.00 \mathrm{CT}$.

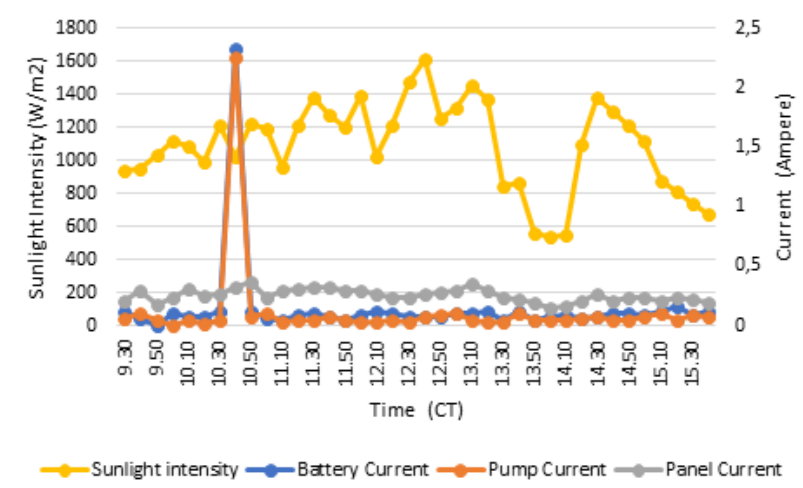

Figure 5. Relationship among battery current, pump current, panel current, and solar radiation intensity with time.

Figure 5 exhibits that the battery current, pump current, panel current, and solar radiation intensity fluctuate. The battery current at 9.30 CT to $15.40 \mathrm{CT}$ has an average value of 0.117809 Ampere, while the highest value of battery current is 2.32 Ampere at $10.40 \mathrm{CT}$ and the lowest value is 0.05 Ampere at $11.10 \mathrm{CT}, 11.50 \mathrm{CT}$. $\mathrm{CT}, 13.30 \mathrm{CT}$ and $13.50 \mathrm{CT}$. The pump current at 9.30 CT to $15.40 \mathrm{CT}$ has an average value of 0.116757 Ampere. The highest value for pump current is 2.25 Ampere at $10.40 \mathrm{CT}$ and the lowest value is 0.02 Ampere at $10.20 \mathrm{CT}$. Then, the panel current has an average value of 0.254211 Ampere. The highest current of the panel is 0.35 Ampere at 13.10 with sunlight intensity of $1458.4 \mathrm{~W} / \mathrm{m} 2$.

As can be seen in Figure 6, the wind speed is directly proportional to the manual pump water discharge. Where the greater the wind speed, the greater the discharge generated by the pump. The highest wind speed is 9.7 $\mathrm{m} / \mathrm{s}$ with a discharge output of $528 \mathrm{~L} /$ hour at $15.20 \mathrm{CT}$.

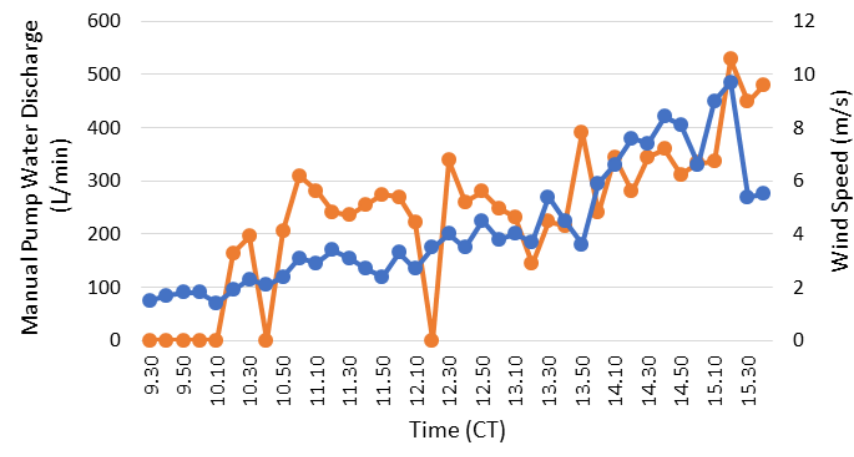

$\multimap$ Manual Pump Water Discharge (L/min) $\quad \longrightarrow$ Wind Speed $(\mathrm{m} / \mathrm{s})$

Figure 6. Relationship between manual pump water discharge and wind speed with time

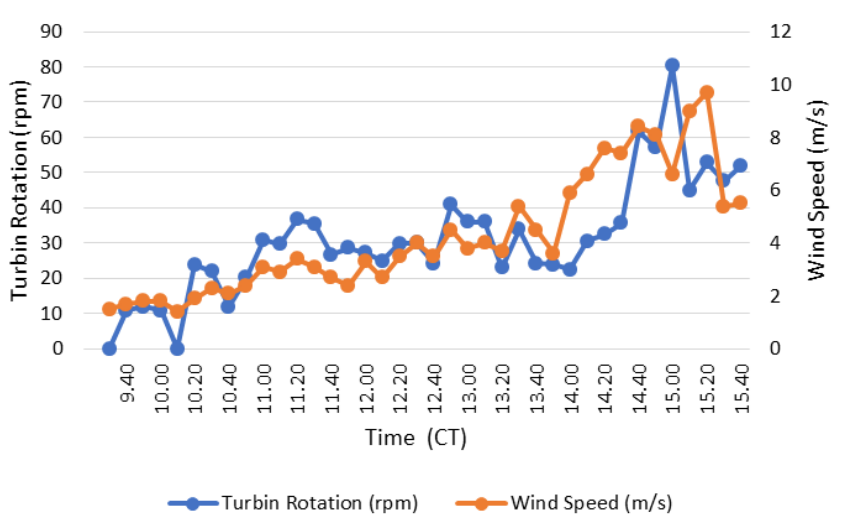

Figure 7. Relationship between wind speed and turbine rotation with time.

As shown in Figure 7, the wind speed is directly proportional to the turbine speed. Where the greater the wind speed, the turbine rotation speed will be greater. Where the highest wind speed is $9.7 \mathrm{~m} / \mathrm{s}$ with a turbine rotation speed of $52.9 \mathrm{rpm}$ at $15.20 \mathrm{CT}$.

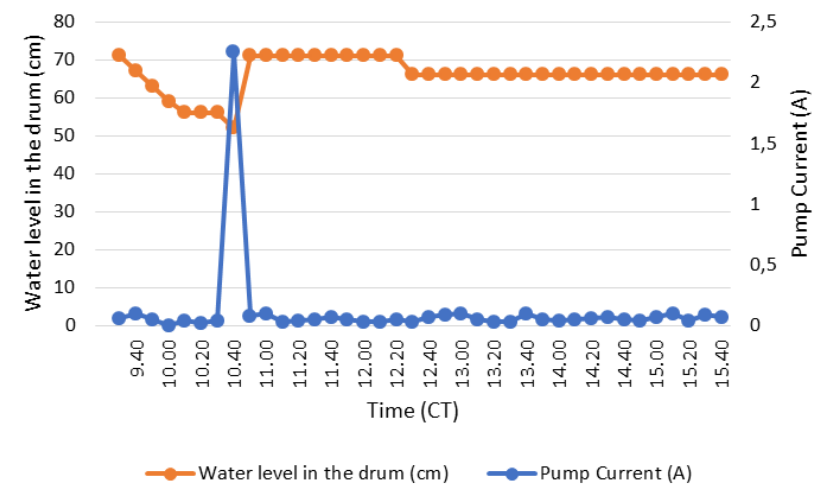

Figure 8. Relationship between pump current, and water level in the drum with time. 
Figure 8 shows that the pump only supplies water to the drum when the water level in the drum reaches 52 $\mathrm{cm}$ with a pump current of 2.25 Ampere at $10.40 \mathrm{CT}$. Meanwhile, at other times, the pump does not supply water to the drum because the water level does not meet the requirements to fill water (water level is below 51 $\mathrm{cm})$.

\section{Conclusion}

Based on the data obtained from testing the tool, the conclusions obtained are:

1. The water supply control device has been successfully made by utilizing wind turbines and Solar Panels.

- The wind turbine rotates with an average speed of $30.87 \mathrm{rpm}$ so that it can drive a manual pump with the highest discharge output of 528 L/hour at $15.20 \mathrm{CT}$.

- Solar Panels are designed with two 50 WP capacity panels to operate a $12 \mathrm{~V}$ DC pump using Arduino Uno.

2. The control system that is made functions to control the continuity of water, where at $10.40 \mathrm{CT}$ the wind speed is $2.1 \mathrm{~m} / \mathrm{s}$ the turbine does not move the manual pump so that the manual pump water discharge $=0 \mathrm{~L} /$ hour, then Arduino Uno gives the servo motor command to open the faucet with a discharge output of $256 \mathrm{~L} /$ hour.

3. The electric pump only delivers water when the ultrasonic sensor sends a signal that the water level reaches $51 \mathrm{~cm}$.

\section{Acknowledgement}

Authors would like to thank Education, Culture, Research and Technology Ministry of Indonesia for funding this applied research through applied research scheme 2021-2023 with Contract Number: 261/E.4.1/AK.04.PT/2021.

\section{References}

[1] Mulyadi, M. dan A. M. Shiddiq Yunus, "Application of Hybrid Solar and Wind Energy Generation for Paddle Wheel Aerator". The $5^{\text {th }}$ International Symposium on Material, Mechatronics and Energy, Gowa 2018.

[2] Supriyadi, Achmad, at al, "Rancang Bangun Sistem Kendali Unit Pengolahan Air Bersih Berbasis Arduino Uno R3 dan Nextion Nx4827t043_011r", (Design and Control System of Clean Water Treatment Units Based on Arduino Uno R3 and Nextion Nx4827t043_011r). Berkala Fisika, Vol. 22, No. 2. 2019.

[3] Andrea B, Danielle, M, and Arianna F,"Modelling water requirements of greenhouse spinach for irrigation management purposes", Hydrology Research, Vol 48, No. 3., December 2016.

[4] https://www.esdm.go.id/en/media-center/news-archives/energyminister-delivers-performance-report-of-2020-and-workprogram-for-2021 (Accessed 15 November 2021).

[5] G. Report, "GWEC forecasts $817 \mathrm{GW}$ of wind power in 2021," 2021. [Online]. Available: https://gwec.net/gwec-forecasts-817gw-of-wind-power-in-2021/.

[6] "\$100 Billion a Year of Global Investment Forecast as Wind Becomes Increasingly Competitive with Conventional Fuels." https://store.frost.com/global-wind-power-market-forecast-to2025.html.

[7] A. M. Shiddiq Yunus and A. Wahdah, "Modification and Testing of Wind Turbine with Double Savonius, Jurnal INTEK, Vol. 3, No. 1, April 2016.

[8] https://www.sciencedirect.com/topics/engineering/solar-panel (Accessed on 15 November 2021). 